\title{
Empirical Research on the College Students' Employability Affect Factors of GIS Major Based on Factor Analysis
}

\author{
Du Fuguang \\ Deptartment of Resource Management \\ Tangshan Normal University \\ Tangshan, Hebei, China
}

\author{
Zhang Yanan \\ Deptartment of Resource Management \\ Tangshan Normal University \\ Tangshan, Hebei, China
}

\begin{abstract}
Factor analysis method was uesd the research on the college students' employability affect factors of GIS major based on 325 college students' effective samples of GIS major of five universities of Hebei Province, China. It used 22 evaluation indicators and extracted 5 evaluation factors to research the affect factors. The result showed that the $\mathbf{5}$ evaluation factors had higher total influence which reached 4.01. The degree of influence ranged from large to small, self-capacity factor, college factor, enterprise factor, government social factor, and family factor. Among them, self-ability factor and university factor played a major role, and their variance contribution rate reached $22.21 \%$ and $17.00 \%$.
\end{abstract}

Keywords-factor analysis; employability; affect factors; GIS

\section{INTRODUCTION}

The employment of college students had always been a key focus issue of our country, government department and university. It was not only related to the realization of personal future and its own value, but also a major event related to social and economic development and social stability[1]. Recent years, with the continuous development of GIS technology, it had been widely used in many fields of national economic construction such as agriculture, forestry, water conservancy, land, transportation, and urban planning. In order to meet the needs of society and the market, many universities set up GIS major. Under the situation of diversified development of the employment market and increasingly fierce employment competition, it was significant for the government department and university to study how to improve their own level and improve their employment. It had urgent practical significance and far-reaching history for rationally guiding the construction and development of GIS disciplines to effectively adapt to the needs of society and the market[2].

Based on the survey data of five universities undergraduate students of GIS major of Hebei Province, the research independently designed questionnaire system of influence factors about the employment of GIS major college studengs of Hebei Province. With the support of SPSS 20.0, the paper used factor analysis model and

Supported by the key research cooperation topic of Department of Human Resources and Social Security of Hebei Province (No.JRSHZ-2018-01057) constructed a scale to extract and analyze the impact of different factors on the employment ability of GIS majors.

\section{EASE OF USE}

\section{A. Questionnaire Compilation}

China scholars completed a lot of research on the influence factors of the employability of college students. For example, Cheng Wei collected and analyzed the statistical data in his paper Research on Employment Ability of College Students, and extracted the factors that affect the promotion of College Students' employment ability. According the result of the research, he proposed the five key factors: specialty setting, career planning, evaluation and incentive, campus culture and teaching ability[3]. Zhao Jun, in his paper The Study on the Employment Ability of College Students Based on Factor Analysis, put forward that physical and mental qualities were the main influence factors of the college students employability, followed by the quality of applicants, professional level, social ability and cultural achievements[4]. Huang Ling and Yang Penghui designed three aspects to evaluate the influence factors of college students' employment in the paper The Study of the Composition of College Students' Employment Ability Based on Principal Component Analysis. They put forward that most influential factors were attitude and cooperation ability, career planning and management, learning and enterprising ability, and professional skills application ability[5].

On the basis of analyzing and summarizing the influence factors of college students' employability, through visiting and investigating the relevant government departments, GIS enterprise, universities and college students of Hebei Province, and based on exploratory factor analysis of the valid samples of the survey data, the paper put forward a pentagonal model of the influence factors of college students employability of GIS major and designed a questionnaire system. Five dimensions were selected as the first-level evaluation factors of the influence factors of the employment of GIS major including government and society, employer, university, self ability, family factor, and 22 variables were selected as the second-level evaluation indicators, including business demand (X11), employment policy (X12), enrollment scale (X13), employment market (X14), 
corporate culture(X21), welfare remuneration(X22), enterprise location(X23), career development(X24), training target(X31), curriculum setting(X32), teaching mode(X33), employment guidance(X34), evaluation and assessment(X35), school-enterprise cooperation(X36), campus culture(X37), physical and mental quality(X41), social ability(X42), learning ability(X43), professional skill(X44), applicant quality(X45), economic situation(X51) and concept of employment(X52).

It used Likert's five-level positive scoring method, and selected 22 secondary indicators to evaluate the data according to the degree of impact. And also according to the five levels of very small impact, small impact, general, large impact, very large impact, the corresponding scores were 1, 2, 3, 4 and 5.

\section{B. Sample Statistics and Test}

At present, there were 5 universities including Hebei Normal University, North China University of Technology, Hebei University of Engineering, Yanshan University and Hebei Geological University set up GIS major in Hebei Province, China. Through the relevant personnel of colleges and universities, 338 samples of data were collected and then removed 13 unqualified questionnaires which the repetition rate was more than $5 \%$. At last, 325 valid statistical samples were collected. The sample efficiency was $97.01 \%$. Meanwhile, Krone Bach's alpha coefficient was used to test the reliability of the questionnaire in SPSS20.0.

$$
\alpha=\left(\frac{k}{k-1}\right) \cdot\left(1-\frac{\sum a_{i}^{2}}{\sum a_{t}^{2}}\right)
$$

Among them, $\alpha$ represented credibility, $\mathrm{k}$ represented the number of items in the scale, $a_{i}$ represented the variance $(i=1$, $2, \ldots \mathrm{k}$ ) of the score of all visitors in item $\mathrm{I}, \mathrm{a}_{\mathrm{t}}$ represented the variance $(t=1,2, \ldots \mathrm{k})$ of the total scores of all visitors, and the total scores refered to the total scores of each item.

The analysis results were shown in Table I.

TABLE I. SAMPLE RELIABILITY TESE VALUES

\begin{tabular}{|c|c|c|c|}
\hline Index Code & Items & Samples & $\alpha$ Coefficient \\
\hline $\mathrm{X} 1$ & 4 & \multirow{5}{*}{325} & 0.793 \\
\hline $\mathrm{X} 2$ & 4 & & 0.748 \\
\hline $\mathrm{X} 3$ & 7 & & 0.900 \\
\hline $\mathrm{X} 4$ & 5 & & 0.891 \\
\hline $\mathrm{X} 5$ & 2 & & 0.782 \\
\hline
\end{tabular}

The results showed that the coefficient of government and society was 0.793 , the coefficient of employer was 0.748 , the coefficient of university was 0.900 , the coefficient of selfability was 0.891 , and the coefficient of family factor was 0.782 . The coefficients of the five dimensions used in the questionnaire were all greater than 0.7 and had high internal consistency.

\section{PROCESS OF RESEARCH AND ANALYSIS}

\section{A. Factor condition test}

Factor analysis of samples was used to get validity test value by SPSS20.0. The follwing Table II showed the results.
TABLE II. KMO AND BARTLETT TEST VALUES

\begin{tabular}{|c|c|c|}
\hline \multicolumn{2}{|c|}{ Kaiser-Meyer-Olkin metric for sampling sufficiency } & 0.929 \\
\hline \multirow{2}{*}{$\begin{array}{c}\text { Bartlett sphericity } \\
\text { test }\end{array}$} & Approximate chi-square & 1306.911 \\
\cline { 2 - 3 } & df & 231 \\
\cline { 2 - 3 } & Sig. & 0.000 \\
\hline
\end{tabular}

In general, the analysis effect was the best when KMO's statistical value was greater than 0.9 . The analysis result showed that $\mathrm{KMO}=0.929>0.9$, so the method of factor analysis was feasible. At the same time, the statistical value Sig. of Bartlett spherical test was 0.000 , far less than 0.05, which further illustrates that there was a strong correlation among the 22 elements.

\section{B. Factor extraction}

The 325 valid samples collected were imported into SPSS 20.0. Factor analysis was carried out by dimension reduction module. Five principal components were obtained by extracting factor characteristic values which was greater than 1 . The scree plot was also obtained which was shown in Fig. 1.

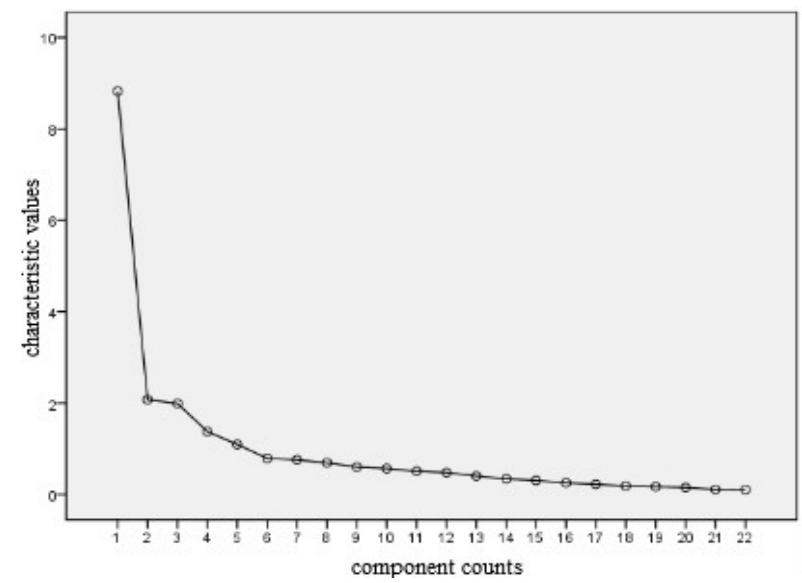

Fig. 1. Characteristic values scree plot

After the fifth factor, the characteristic values of the components were less than 1 , and the change of the characteristic values was slow. Therefore, according to the principle that the characteristic values were greater than 1 , the first five factors were extracted. In order to get more detailed analysis results, the samples were rotated orthogonally and converged after 9 iterations. The results showed that the cumulative variance contribution rate of the extracted common factors reached $69.811 \%$, which contained most of the data information of the original variables. Therefore, the original 22 variables were classified into 5 evaluation factors for analysis. The results were shown in Table III. 
TABLE III. RESULTS OF FACTOR ANALYSIS

\begin{tabular}{|c|c|c|c|c|}
\hline Common Factor & Evaluate Indicator & Factor load & Characteristic Values & VCR \\
\hline \multirow{5}{*}{$\begin{array}{c}\text { Y1 } \\
\text { Self ability }\end{array}$} & X43 & 0.817 & \multirow{5}{*}{4.887} & \multirow{5}{*}{$22.21 \%$} \\
\hline & $\mathrm{X} 44$ & 0.805 & & \\
\hline & $\mathrm{X} 45$ & 0.776 & & \\
\hline & $\mathrm{X} 42$ & 0.708 & & \\
\hline & X41 & 0.675 & & \\
\hline \multirow{7}{*}{$\begin{array}{c}\text { Y2 } \\
\text { Universiy }\end{array}$} & X32 & 0.769 & \multirow{7}{*}{3.741} & \multirow{7}{*}{$17.00 \%$} \\
\hline & X33 & 0.739 & & \\
\hline & $\mathrm{X} 31$ & 0.735 & & \\
\hline & X36 & 0.734 & & \\
\hline & X34 & 0.644 & & \\
\hline & X35 & 0.635 & & \\
\hline & X37 & 0.633 & & \\
\hline \multirow{4}{*}{$\begin{array}{c}\text { Y3 } \\
\text { Employer }\end{array}$} & $\mathrm{X} 22$ & 0.751 & \multirow{4}{*}{2.607} & \multirow{4}{*}{$11.85 \%$} \\
\hline & $\mathrm{X} 21$ & 0.750 & & \\
\hline & X24 & 0.645 & & \\
\hline & $\mathrm{X} 23$ & 0.516 & & \\
\hline \multirow{4}{*}{$\begin{array}{c}\text { Y4 } \\
\text { Government and society }\end{array}$} & $\mathrm{X} 12$ & 0.850 & \multirow{4}{*}{2.220} & \multirow{4}{*}{$10.09 \%$} \\
\hline & $\mathrm{X} 14$ & 0.765 & & \\
\hline & $\mathrm{X} 13$ & 0.744 & & \\
\hline & $\mathrm{X} 11$ & 0.554 & & \\
\hline \multirow{2}{*}{$\begin{array}{c}\text { Y5 } \\
\text { Family factor }\end{array}$} & $\mathrm{X} 52$ & 0.878 & \multirow{2}{*}{1.903} & \multirow{2}{*}{$8.65 \%$} \\
\hline & $\mathrm{X} 51$ & 0.818 & & \\
\hline
\end{tabular}

It was found that the first principal component included five indicators: learning ability, professional skill, applicant quality, social ability, physical and mental quality, which reflected the impact of their own quality. The second principal component included seven indicators, including curriculum setting, teaching mode, training target, school-enterprise cooperation, employment guidance, evaluation and assessment, and campus culture, which reflected the impact of university. The third principal component included four indicators, including welfare remuneration, corporate culture, career development, and enterprise location, which reflected the impact of enterprise. The fourth principal component included four indicators: employment policy, employment market, enrollment scale and business demand, which reflected the impact of the government and society. The fifth principal component included the concept of employment and economic situation, which reflected the impact of the family.

\section{Comprehensive evaluation function calculation}

In order to reflect the affect factors of employment ability of GIS major, factor analysis was needed to find out the comprehensive impact. factor scores coefficient matrix was obtained by the analysis of effective samples. The results were shown in Table IV.

TABLE IV. FACTOR SCORES COEFFICIENT MATRIX

\begin{tabular}{|c|c|c|c|c|c|}
\hline \multirow{2}{*}{ Evaluation Index } & \multicolumn{5}{|c|}{ Component } \\
\hline & 1 & 2 & 3 & 4 & 5 \\
\hline X11 & -0.088 & -0.003 & 0.38 & 0.273 & 0.297 \\
\hline $\mathrm{X} 12$ & -0.056 & -0.105 & 0.392 & 0.055 & 0.018 \\
\hline $\mathrm{X} 13$ & -0.041 & 0.161 & 0.298 & -0.015 & -0.094 \\
\hline $\mathrm{X} 14$ & -0.038 & -0.009 & 0.339 & 0.012 & -0.112 \\
\hline X21 & -0.071 & -0.120 & 0.033 & 0.468 & 0.034 \\
\hline X22 & 0.204 & -0.006 & 0.001 & 0.161 & 0.079 \\
\hline $\mathrm{X} 23$ & 0.131 & -0.070 & 0.027 & 0.190 & 0.031 \\
\hline $\mathrm{X} 24$ & 0.160 & -0.001 & -0.051 & 0.110 & 0.020 \\
\hline X31 & -0.020 & 0.098 & 0.008 & 0.219 & -0.060 \\
\hline X32 & -0.104 & 0.167 & -0.005 & 0.235 & -0.122 \\
\hline $\mathrm{X} 33$ & -0.001 & 0.221 & 0.001 & 0.198 & -0.122 \\
\hline X34 & -0.067 & 0.321 & 0.003 & -0.143 & -0.025 \\
\hline $\mathrm{X} 35$ & -0.047 & 0.246 & -0.043 & -0.131 & 0.146 \\
\hline X36 & 0.085 & 0.208 & -0.017 & -0.110 & -0.026 \\
\hline $\mathrm{X} 37$ & -0.075 & 0.299 & -0.074 & -0.073 & 0.029 \\
\hline $\mathrm{X} 41$ & 0.173 & 0.016 & -0.026 & -0.046 & -0.019 \\
\hline $\mathrm{X} 42$ & 0.233 & 0.048 & -0.082 & -0.282 & 0.067 \\
\hline $\mathrm{X} 43$ & 0.226 & -0.065 & -0.076 & 0.007 & -0.018 \\
\hline $\mathrm{X} 44$ & 0.232 & $\begin{array}{l}-0.089 \\
\end{array}$ & 0.034 & -0.068 & -0.056 \\
\hline $\mathrm{X} 45$ & 0.214 & -0.055 & 0.035 & -0.104 & -0.005 \\
\hline X51 & 0.018 & -0.037 & -0.001 & -0.077 & 0.456 \\
\hline X52 & -0.017 & -0.009 & -0.086 & 0.021 & 0.502 \\
\hline
\end{tabular}


The expression of factor score was obtained as follows.

$$
\mathrm{Y}=\sum_{\mathrm{m}=\mathbf{l}}^{\mathrm{n}} \mathrm{\alpha}_{\mathrm{ij}} \cdot \mathrm{X}_{\mathrm{ij}}
$$

Among them, $\mathrm{m}, \mathrm{n}$ were the evaluation index number, $\alpha$ was the score coefficient of the evaluation factor of the current component, $\mathrm{X}$ was the mean of the original data after the standardization, $Y$ was the score of the current factor, $i$ and $j$ stood for the serial number of the current factor and the evaluation index respectively.

According to the formula, the first principal component expression was $\mathrm{Y} 1=-0.088 \mathrm{X} 11-0.056 \mathrm{X} 12-0.041 \mathrm{X} 13-$ $0.038 X 14-0.071 X 21+0.204 X 22+0.131 X 23+0.16 X 24-$

$0.02 \times 31-0.104 \times 32-0.131 \times 33-0.067 \times 34-$

$0.047 \times 35+0.025 \times 36-$

$0.075 \mathrm{X} 37+0.173 \mathrm{X} 41+0.233 \mathrm{X} 42+0.226 \mathrm{X} 43+0.232 \mathrm{X} 44+0.214$

$\mathrm{X} 45+0.018 \mathrm{X} 51-0.017 \mathrm{X} 52$.

Similarly, other factors Y2, Y3, Y4, and Y5 could be scored. After calculation, the final factor score was: selfability factor $\mathrm{Y} 1=4.51$, university factor $\mathrm{Y} 2=4.35$, employer factor $\mathrm{Y} 3=3.83$, government and social factor $\mathrm{Y} 4=3.34$, family factor $\mathrm{Y} 5=3.03$.

The expression of the overall influence degree [6]:

$$
\mathrm{Y}=0.318 \mathrm{Y} 1+0.244 \mathrm{Y} 2+0.17 \mathrm{Y} 3+0.145 \mathrm{Y} 4+0.124 \mathrm{Y} 5
$$

After calculation, $\mathrm{Y}=4.01$.

\section{Index weight and inflience degree score}

Calculated the weight of each factor according to the variance contribution rate of the five extracted components, and analyzed the influence degree of the sample data. The results were shown in Table V.

\begin{tabular}{|c|c|c|c|}
\hline Component & Secondary Level Index & Influence Degree & Relative Weight \\
\hline \multirow{5}{*}{1} & $\mathrm{X} 43$ & 4.22 & \multirow{5}{*}{$31.82 \%$} \\
\hline & $\mathrm{X} 44$ & 4.31 & \\
\hline & $\mathrm{X} 45$ & 4.07 & \\
\hline & $\mathrm{X} 42$ & 3.73 & \\
\hline & $\overline{\mathrm{X} 41}$ & 3.95 & \\
\hline \multirow{7}{*}{2} & X32 & 3.86 & \multirow{7}{*}{$24.36 \%$} \\
\hline & X33 & 3.74 & \\
\hline & X31 & 3.82 & \\
\hline & X36 & 3.79 & \\
\hline & X34 & 3.71 & \\
\hline & X35 & 3.46 & \\
\hline & X37 & 3.38 & \\
\hline \multirow{4}{*}{3} & X22 & 4.00 & \multirow{4}{*}{$16.97 \%$} \\
\hline & X21 & 3.44 & \\
\hline & X24 & 4.05 & \\
\hline & $\mathrm{X} 23$ & 3.89 & \\
\hline \multirow{4}{*}{4} & $\mathrm{X} 12$ & 3.49 & \multirow{4}{*}{$14.45 \%$} \\
\hline & X14 & 3.46 & \\
\hline & $\mathrm{X} 13$ & 3.49 & \\
\hline & $\mathrm{X} 11$ & 3.62 & \\
\hline \multirow{2}{*}{5} & X52 & 3.03 & \multirow{2}{*}{$12.39 \%$} \\
\hline & $\mathrm{X} 51$ & 2.96 & \\
\hline
\end{tabular}

TABLE V. RELATIVE WEIGHT AND INFLUENCE DEGREE

The analysis result showed that self-ability had the greatest impact, with its relative weight reached $31.82 \%$, followed by university reached 24.36\%. Employers, government and social levels reached $16.97 \%$ and $14.45 \%$ respectively. Family factor was the smallest impact reached $12.39 \%$. From the single value of the impact, the highest score were professional skills (4.31), the lowest was family economic status (2.96).

\section{CONCLUSIONS}

- According to the mathematical model of factor analysis, the influence degree of the five factors on the employment ability of GIS major was self-ability factor, university factor, employer factor, government social factor and family factor. The highest influence degree of self-ability was professional skill. The highest influence degree of university was curriculum setting. The highest influence degree of employer was welfare remuneration. The highest influence degree of government and social was the business demand. The highest influence degree of family factor was the concept of employment.

- The overall influence degree of the selected evaluation factors which researched 4.0 were relatively high considered by the college student of GIS major. Among them, the factors of self-ability and university generally had a greater impact, the scores were 4.51, 4.35, significantly higher than the other several factors. Therefore, these two aspects should be emphasized in order to improve the employability of GIS major college students.

- Self-ability factor was the most important factor. According to the calculation, the variance contribution rate of self-ability factor reached $22.21 \%$, and its weight reached $31.82 \%$, which was significantly higher than other factors.

The research showed that there was a high degree of correlation, interdependence and mutual restriction among the factors. Therefore, in order to improve the employment ability of the college students of GIS major, it is necessary to improve their own ability level, clarify the training objective of colleges and universities, improve and perfect the training program, set up courses reasonably and carry out corresponding teaching modes. It is necessary not only to change the existing assessment methods of emphasizing theory and neglecting practice in most colleges and universities, but also to change the standards and methods of the results of GIS personnel training, so as to make it tend to pay equal attention to both theory and practice assessment, and pay equal attention to the training of skilled and innovative personnel.

\section{REFERENCES}

[1] Zhang Hesheng. "Ethical review and empirical research on fairness of national college entrance”. Central South University, 2013. (In Chinese).

[2] Zhang Yue. "Employment market analysis of GIS major". Liaoning Normal University, 2007. (In Chinese). 
[3] Cheng Wei. "Empirical research on employment ability and promotion of college students”. Exp loration of Higher Education, vol. 7, pp. 98-105, July 2017. (In Chinese).

[4] Zhao Jun. "Empirical research on the employability of college students based on factor analysis”. Modern Education Management, vol. 2, pp. 119-123, February 2015. (In Chinese).
[5] Huang Ling, Yang Penghui. "Research on the composition of employability of college students based on principal componen analysis”. Journal of Guiyang University (Natural Science Edition), vol.11, pp. 5-10, June 2016. (In Chinese).

[6] Lin Longfei, Huang Guanghui, Wang Yan. "Research on the authenticity evaluation of ethnic cultural tourism products based on factor analysis". Human Geography, vol. 25, pp. 39-43, February 2010. (In Chinese). 